Muhammad Akram, Lubna Shabnaz and Surayya 93

\title{
An Analysis of Male Internal Migration and Its Correlation to Employment Status: Evidence from the Punjab
}

\author{
Muhammad Akram, Lubna Shahnaz and Surayya*
}

\section{Introduction}

Migration plays a pivotal role in the reallocation of human resources under changing demand and supply conditions. Migration takes place when an individual decides that it is preferable to move rather than to stay and where the difficulties of moving seem to be less than the expected rewards. In recent years there has been a trend of increasing migration rates. The United Nations (2000) estimates that about 140 million persons (roughly 2 per cent of the world's population) reside in a country where they are not born. ${ }^{1}$ Usually migration takes place from the regions that are associated with poverty and insecurity towards regions which offer greater security of life, employment and basic social services. Poverty pushes people to migrate to urban areas-the outcome, the world's urban population approaches 2.3 billion by 1990 with 61 per cent living in the metropolitan areas of developing countries and touches 66 per cent in 2000 (United Nations). Within the world Asia has about 15 of the largest cities of the world and most of them are growing at more than 5 per cent per annum. Increased rate of natural growth, immigration and rural-urban migration might be the causes of such a high rate of growth of urban population.

Pakistan's migration rates are highest as indicated by the urbanisation experience which is among the highest in Asia (Marwat, 1998). Population Labor Force and Migration Survey (PLM) 1979 explains that the share of rural-urban migration in total internal migration in 1972-79 was 29.8 per cent, while in 1978-79 this share increased to 38.42 per cent. According to the Population Census 1998, the urban/rural break up reveals that one in three persons live in urban areas as the share of rural population has declined by 4.2 per cent from 71.7 per cent in 1981 to 67.5 per cent in 1998. The other internal migration direction during the same period is as follows: rural to rural migration decreases from 41.3 per cent in 1972-79 to

\footnotetext{
*M. Akram and Lubna Shahnaz are doctoral candidates of economics at the Quaid e Azam University, Islamabad while Surayya is a lecturer at the International Islamic University (Women's Campus) Islamabad.

The authors are thankful to Ms. Zainab Kizilbash, Specialised Honours Graduate, York University, Canada for her sincere and valuable cooperation during this paper.

${ }^{1}$ http://www.wider.unu.edu
} 
20.3 per cent in 1996-97, while urban to rural migration direction decrease 13.9 per cent to 36.9 per cent, and urban to urban migration increases 14.9 per cent to 43 per cent during the same period. ${ }^{2}$

This increase occurred in spite of the relatively high cost of living in urban areas and relatively high urban unemployment rate. According to Todaro (1969) the expected urban to rural wage differential is the actual motivation for migration. Agesa (2000) explains this rural-urban wage differential and the gains in returns to observable productivity by stating that enhancing attributes may be a more accurate measure of the incentive to migrate. Migration literature suggest two further explanations for this phenomenon, first, non-economic factors may be a predominant influence on the migration decision. Bilsborrow et.al (1986) explain that high population density in rural areas may lead to an outflow of some of the rural population to urban areas. Second, Oucho (1998), suggests that social comforts and better housing attracts rural migrants to the city. So the economic theory, which perceives migration as an investment in human capital, is based on the maximisation behaviour of individuals. It measures the responsiveness of migration to the difference in earnings at different locations.

In the context of the increasing migration inflow in urban areas of Pakistan, the employment status of individuals is an extremely important issue, which must be analysed with respect to migration direction. Rapid urbanisation has required response by policy makers and planners to deal with this pressure created on the infrastructure of large urban centers by the influx of migrants. Several studies have been carried out in Pakistan to explore different dimensions of migration status in Pakistan. ${ }^{3}$ However, we could not find even a single study to investigate the role of employment status by migration direction in Pakistan.

This paper fills this gap and examines the factors that influence migration direction with special reference to employment status of the migrants (only male). ${ }^{4}$ It also takes into account the individual's personal and household characteristics: age, education, marital status and household financial status etc. A reduced form model is estimated and this model portrays the decision making by the migrants as a simultaneous process as

\footnotetext{
${ }^{2}$ For details about data for the year 1972-79 see Demery and Arif, 1983 and for 1996-97 consult Khan and Shahnaz 2000.

3 See. For example, Irfan et.al (1983); Irfan (1986); Perveen (1993); Ahmed and Sirageldin (1994); Arif and Irfan (1997); Khan and Shahnaz (2000); Akram et.al (2001).

${ }^{4}$ Only male migrants are analysed because according to the Population Census (1998) about 97.4per cent females move from one place to another only because of noneconomic reasons in Punjab.
} 
suggested by Greene (1992), and it translated into the multinomial logit model for estimation. In the present study we have used the multinomial logit model to analyse the relationship between migrants and their employment status by using the Pakistan Integrated Household Survey 1998-9. Within Pakistan, the volume of migrants is 6,701,256 in Punjab, which is 9 per cent of the population of the province (Population Census 1998). In urban areas 15.2 per cent are migrants while in the rural areas 6.4 per cent are migrants. Punjab has been used for our analysis because it offers the richest data on migration rates, as it is Pakistan's most populated province. 'The migration rate in Punjab is the highest when compared to other provinces.

\section{Estimation Method}

To examine the direction of migration decision of an individual we carry out a multivariate analysis. Our dependent variable in this model is categorised into five mutually exclusive categories. We assume that an individual in Punjab chooses from amongst five mutually exclusive and exhaustive alternatives available to him. These alternatives about the migration decision of an individual can take various options: first, the physical movement of individuals along with the change of residence from rural areas to urban areas (RUM) for any reason across the administrative district. Secondly, the physical movement of individuals along with the change of residence from urban areas to urban areas (UUM) for any reason across the administrative district. Thirdly, the physical movement of individuals along with the change of residence from rural areas to rural areas (RRM) for any reason across the administrative district. Fourth, the physical movement of individuals along with the change of residence from urban areas to rural areas (URM) for any reason across the administrative district. The last option is considered of individuals who do not physically move and have been living in the same place since birth (NM). These alternatives are categorised as 1,2,3,4, and 0 respectively. Akram et.al (2001) empirically analysed these alternatives by using the multinomial logit model. We used the same methodology for our empirical analysis.

Assuming that the errors in this model are independently and identically distributed with Weibull distribution then the difference between the errors has a logistic distribution (Greene (1992) and the multinomial logit is the appropriate technique of estimation. The probabilities in the multinomial logit model are therefore given by

\footnotetext{
${ }^{5}$ Punjab constituted 56.1per cent of the total population of Pakistan.
} 


$$
\begin{gathered}
\operatorname{Prob}(Y=j)=\frac{e^{\beta_{j} x_{i}}}{1+\sum_{k=1}^{J} e^{\beta_{k}^{\prime} x_{i}}} \\
\operatorname{Prob}(Y=0)=\frac{1}{1+\sum_{k=1}^{J} e^{\beta^{\prime} x_{i}}} \quad \text { for } j=1,2,3 .
\end{gathered}
$$

where coefficients $\beta$ 's are normalised to zero and $\mathrm{x}$ is the vector of explanatory variables. The multinomial logit model is identified by normalising the coefficient of one of the categories to zero. Hence we normalise the coefficient of the alternative of non migrant to zero.

The coefficients in our models are difficult to interpret because they only provide information on the effects of independent variables on the odds ratio. To interpret the effects of independent variables $(x)$ on the probability of each category of migration we calculate partial derivatives as

$\frac{\partial P}{\partial X}=P_{j}\left(1-P_{j}\right) \beta_{x j}-\sum_{k} P_{j} P_{k} \beta_{x k} \quad$ where $j, k=1,2,3$

where $\mathrm{P}$ is the probability of being a member of each alternative. The $\log$ of likelihood function is defined by defining for each individual $\mathrm{d}_{\mathrm{ij}}=$ 1 if alternative category $j$ is chosen for individual $i$, and 0 if not, for the other possible outcomes. Then for each individual $i$, one and only one of $d_{i j}$ 's is one (Greene (1992). The log likelihood function is given by

$\ln L=\sum_{i} \sum_{j} d_{i j} \ln \operatorname{Pr} o b\left(Y_{i}=j\right)$

Our model is based on the assumption that the five alternatives available for the migration decision of an individual are independent of each other. It is also assumed that for each individual all five options are simultaneously open. The parameters for each category of migration decision in each model are obtained from the estimation of a single maximum likelihood logit.

\section{Data and Variables}

The data on migration used in the analysis are obtained from the original data tapes of the Pakistan Integrated Housebold Survey, 1998-99 conducted by the Federal Bureau of Statistics of the Government of Pakistan. This 
nation wide survey records complete information on household composition: education, health, population, labour market activities, household expenditure, income and migration status, etc. ${ }^{6}$ The PIHS (1998-99) is based on a sample of 16,305 households and 114,996 individuals enumerated during the year 1998-99 all over Pakistan. Total sample consists of 66,656 population of ages 10 years and above having 36,384 males. A sample of 14,743 males drawn from the survey for Punjab consisting of 3383 migrants and 11,360 non-migrants.

\section{Measuring Dependent and Independent Variables}

We use migrants/non-migrant aged 10 and above for the units of observation in our empirical analysis. As was noted earlier, there are five different categories of migration direction from which an individual can decide to move. These combinations are 1) rural to urban migration, 2) urban to urban migration, 3) rural to rural migration, 4) urban to rural migration, 5) non-migration. Hence dependent variables in our analysis are $R U M, U U M, R R M, U R M$ and $N M$. The detailed explanation of both dependent and explanatory variables of the model is defined in Table 1 . It is convenient to describe explanatory variables in various groups. The explanatory variables are those factors that may be affecting an individual's decision to migrate-not migrate from one place to another. The first set of explanatory variables are the individual characteristics that include the age of the individual in completed years, age squared is included to capture the non-linear effect of individual age on the dependent variable. The educational status of the individual: primary, secondary and higher, which is given by three dummy variables, by keeping illiteracy as the base category. Marital status of the individual is also used as the dummy variable if the individual is unmarried. Second set of variables comprises individual employment status, which includes dummy variables for the employer, employee, unpaid family helpers and others, while self-employed is used as the base category. Third are household characteristics where we measure family type and ownership of the house, also introduced by the dummy variables. Fifth, is the economic status of the household: which measures per capita monthly income of the household in rupees.

Summary statistics of the variables as reported in Table 2 present some interesting patterns of migration status. As was mentioned earlier individuals of age 10 years and above are included in the sample. The mean age of the migrants is higher than that of non-migrants. The migration patterns show that migrants of age 37 years migrate from urban to urban

\footnotetext{
${ }^{6}$ Details are available in Pakistan Integrated Household Survey (1998-99).
} 
areas, about 39 year of age migrate from rural to urban area and about 42 and 43 years migrate from rural to rural, urban to rural areas respectively. About 21 per cent migrants with primary education have migrated from urban to rural areas. With secondary education there is less tendency to move from rural to rural areas. Migrants with higher education migrate either from rural areas to urban areas or from urban to urban areas, which is about 13 and 27 per cent respectively. Majority of unmarried migrants migrate from urban to urban or from rural to urban areas, which are about 40 and 31 per cent respectively. The highest percentage of paid employees have moved from rural to the urban areas ( 42 per cent), followed by the employees who have moved in the urban-urban direction. The movement of the employer is very low in all the four migratory flows. The highest percentage of the employers has migrated from rural areas to the urban areas. The highest percentage of the self-employed male workers has migrated from one rural area to another rural area, which is about 39 per cent. Similarly the highest percentage ( 11.1 per cent) of the unpaid workers has moved from one rural area to another rural area. About 57 per cent migrants who have migrated from urban to urban areas belong to nuclear families. About 59 and 54 per cent migrants who have their own houses have migrated to the rural areas. Per capita annual income of the households is highest for those males who have migrated to urban areas perhaps due to the better economic opportunities available in the urban areas.

\section{Empirical Estimates of Multinomial Logit Model}

We estimate a multinomial logit model on migration decision direction on its various components. The estimated parameters for each category of the individual, i.e. RUM to $N M$ are obtained from a single maximum likelihood multinomial logit model by using the data from Pakistan Integrated Household Survey 1998-99. Table 3 reports probability derivatives at the mean of the explanatory variable in bold letters followed by the estimated parameters while their asymptotic t-statistics are included in parentheses.

We find that age of the individual has a positive and significant effect on migration in all the four migratory flows while age squared has a negative and significant effect on migration except urban-rural migration, where it is negative but insignificant. The expected gains in initial earnings continue to provide young adults with strong incentives to migrate from the rural areas.

Primary education has a positive and significant effect on migration decision from rural to rural areas. Migrants with secondary education are 
about 4 per cent less likely to move from rural to rural area, while about 3 per cent are more likely to move from urban to urban areas. As educational level of migrants increased the probability of moving towards urban areas increased, as educational level was observed in the case of urban to urban migration. Migrants with primary education are about 1 per cent more likely to migrate, those with secondary education about 3 per cent more likely, and with higher education about 6 per cent more likely to migrate. The effect is also statistically significant in the case of secondary and higher education. The main reasons for migration in urban-urban migratory flow are economic. ${ }^{7}$ Highly qualified people move from one urban center to another in search of better economic opportunities. About 8 per cent of migrants with higher education are less likely to migrate from rural to rural areas. It is less likely that an individual who is living in the rural area will move when he is unmarried and this effect is significant as well. It is about 2 per cent less likely that an unmarried individual will migrate from a rural to a rural area, while he is about 1 per cent more likely to migrate from an urban to urban area.

Employment status in the area of origin is crucial for the possibility of migration. Those who are self employed either in agriculture or in business, are less likely to migrate as compared to those who are either unemployed or work for private or public agencies. Employer's effect on migration is positive only in the case of rural-rural migratory flow. This effect is insignificant as well. It is about 1 per cent more likely that a male employer will move in the rural-rural direction. The employers may belong to the agricultural occupation and move in a rural-rural direction. Agricultural occupation has positive and highly significant effect on migration from one rural area to another rural area Akram et.al (2001). Employer's effect on migration is significant only in the case of urban-urban migratory flow, where it is negative. It is 4 per cent less likely that a male employer will move in the urban-urban direction.

Employee's tendencies to move towards urban areas are prominent. Employee's effect on migration is positive in the case of rural-urban and urban-urban migratory flows. This effect is significant only in the case of rural-urban migration. It is about 4 per cent more likely that a paid employee will move in a rural-urban direction. Usually the wage rates are more competitive in urban areas and that may be the reason for paid employees to move to the urban areas. Unpaid family workers are about 6 per cent less likely to move from rural to urban areas or urban to urban areas and about 1 per cent less likely to move from urban to rural areas. The effect is also

\footnotetext{
${ }^{7}$ See Akram et.al (2001).
} 
statistically significant. Unpaid workers migration flow is positive in case of rural to rural migration. However the effect is statistically insignificant.

The effect of the nuclear family is positive and significant in all the four migratory flows except urban-rural migration, where it is positive but insignificant. It is 2.2 per cent more likely that a person with a nuclear family will migrate from an urban to an urban area and 1 per cent more likely that he will move from a rural to a rural area, while it is 0.4 per cent more likely that he will migrate from a rural to an urban area. The reason behind the positive pattern in all the migration direction is that to move with a nuclear family is much easier than joint/extended families. Owning a house has a negative and significant effect in all the migratory flows except urban to rural flow where it is positive but insignificant. Per capita annual income of the household has a positive and highly significant effect on migration to urban areas. It has a negative and highly significant effect on migration to rural areas showing that households with better financial status can afford to migrate towards urban areas, as was observed urban areas have expensive cost of living as compared to rural areas. It is also because of the wage differential between the rural and urban areas.

\section{Conclusion and policy implications}

This paper was an attempt to identify those factors that influence the physical movement of an individual along with the change of residence from one place to another for any reason across the administrative district in the Punjab by using data from the Pakistan Integrated Household Survey 1998-99 and by estimating a multinomial logit model.

The present study has analysed the process of internal migration within the general theoretical framework of human capital theory which views migration as an investment with accompanying costs and returns. To analyse whether the migration decision is a rational choice in expectations of economic rewards in the destination or not, the classification of economic versus non-economic migrants was used to categorise the sample of migrants. The statistical analysis showed that the migrant population in the PIHS 1998-99 is mostly composed of males and females. The males undertook the decision of migration for economic motives, while the females' decision to migrate is based on non-economic motives such as marriages.

The pattern of male internal migration is more evident predominantly in the urban-urban migratory flow than in rural-urban migratory flow. The reversal of the main direction of migration from the 
rural-urban direction to urban-urban direction is an important finding from the PIHS 1998-99. This is an indication of changed pattern of population distribution from rural-urban shift to urban-urban movements. We find that the individual's decision to migrate in the Punjab is significantly influenced by his age, education level, family type, marital and employment status. The age variable reflects that the probability of migration increases with age. The possibility of getting a better-paid job is one of the crucial factors that affects the direction of migration decision.

Education plays an important role in setting the direction of all the migratory flows. The encouraging findings regarding migration, as a human capital investment is the significantly positive effect of education in terms of completed years of schooling on the probability of migration. The results indicate that additional years of schooling increase the probability of migration. That is why individuals with higher education are moving towards urban centers to get the benefits of better economic opportunities. Higher education appears to have a stronger effect on the probability of migrating than primary, secondary and college level education. Taken together these results do imply that there is evidence of the migration decision being positively linked to the human capital embodied in the individual.

Employment opportunities for highly educated young people are relatively skill specific. Few local employment opportunities for educated persons compel them to stay in their areas of origin and are more likely to take jobs that poorly match their specific skills. They get a lower wage job there as compared to higher wage job which could be attained by migration to that area where their skills better match employer needs. We also find the evidence on employers' migratory flow from rural to rural areas, which shows that they are providing agriculture related job opportunities there. Unpaid family workers move from one rural area to another rural area, while paid employees move towards urban areas. This phenomenon indicates that the wage structure is more competitive in urban areas. The results for selfemployed workers indicate that the probability of migration is lower among the people who operate their own farm, business or industry as compared to government and private employees. The significantly negative coefficients of nuclear family reveal that belonging to a nuclear family system decreases the probability of migration or that belonging to an extended/joint family system increases the probability of migration. 
Table 1: Definition of Variables

\begin{tabular}{ll}
\hline Variables & Description \\
Dependent Variables \\
$R U M$ & $=1$, if the physical movement of individual along with \\
& the change of residence from rural area to urban area for \\
& any reason across the administrative district. \\
& $=2$, if the physical movement of individual along with \\
& the change of residence from urban area to urban area \\
$U U M$ & for any reason across the administrative district. \\
& $=3$, if the physical movement of individual along with \\
& the change of residence from rural area to rural area for \\
& any reason across the administrative district. \\
& $=4$, if the physical movement of individual along with \\
& the change of residence from urban area to rural area for \\
any reason across the administrative district. & $=0$, if the individuals did not physically move and are \\
& living in the same place since birth.
\end{tabular}

\section{Explanatory Variables}

\section{Male Characteristics}

$A G E \quad$ Age of the male in complete years.

AGES Age of the male in complete years squared.

PRIMARY = 1 if individual highest level of completed education is primary schooling and 0 otherwise.

SECONDARY = 1, if individual highest level of completed education is secondary schooling and 0 otherwise.

HIGH = 1 , individual highest level of completed education is 10 years and above schooling and 0 otherwise.

UNMAR $\quad=1$, if the individual marital status is unmarried and 0 otherwise.

\section{Male Employment Status}

EMPLOYER $=1$, if the individual employment status is an employer: ${ }^{8}$ employing less than 10 and more than 10 persons and 0 otherwise.

\footnotetext{
${ }^{8}$ A person who has employed one or more persons, on continuous basis, during the reference period, is defined as employer. He may run an enterprise by himself or with one or more persons.
} 


\begin{abstract}
EMPLOYEE $=1$, if the individual employment status is paid employee, ${ }^{9}$ and 0 otherwise.

SELF EMPL $\quad=1$, if the individual employment status is self-employed: ${ }^{10}$ unpaid family helper and self employed, and 0 otherwise.

UNPAID $\quad=1$, if the individual employment status is unpaid family helper ${ }^{11}$ and 0 otherwise.

OTHERS $=1$, if the individual belongs to some other employment status, which is mentioning above and 0 otherwise.
\end{abstract}

\title{
Household Characteristics
}

$\begin{array}{ll}\text { FTYPE } & =1 \text { if individual lives in a nuclear family }{ }^{12} \text { and } 0 \\ \text { otherwise } & =1 \text {, if the individual has his own house and } 0 \text { otherwise. }\end{array}$

\section{Economic Status of the Household}

PERINCOM Per capita annual income of the household in rupees.

\footnotetext{
${ }^{9}$ A person who works for a public or private employer and receives remuneration in wages, salary, commission, tips, piece rates or pay in kind. It includes regular paid employee, casual paid employee, paid worker by piece rate or service performed, paid non-family apprentices.

${ }^{10}$ A person who during the reference period performed some work for profit and family gain, in cash or in kind on a job where the remuneration is directly dependent upon the profits, or the potential profits, derived from the goods and services produced. Self employed persons do not get assistance from anyone, not even from unpaid family helpers. And own account non-agricultural worker: an own account worker is a person who operates his or her own economic enterprise or engages independently in a profession or trade and hires no employees, However, he/she may get the assistance of unpaid family helpers. Owner cultivator: means a person who cultivates his/her own land. Share cropper: means a person who cultivates land owned by others on the basis of sharing the produce. Contract cultivator: means a person who cultivates land owned by others on rent.

${ }^{11}$ A person who works for pay in cash or in kind in an economic enterprise operated by a member of his/her household or other related persons is termed as unpaid family worker.

${ }^{12}$ Nuclear Family is one consisting of a head, spouse and unmarried sons or daughters.
} 
Table 2: Summary Statistics of Sample $(N=14742)$

\begin{tabular}{|c|c|c|c|c|c|}
\hline Variables & $\boldsymbol{R U M}$ & $\boldsymbol{U U M}$ & $\boldsymbol{R R M}$ & URM & $\mathbf{N M}$ \\
\hline \multicolumn{6}{|c|}{ Individual's Characteristics } \\
\hline$A G E 1$ & $\begin{array}{l}39.548 \\
(18.998)\end{array}$ & $\begin{array}{l}37.952 \\
(19.171)\end{array}$ & $\begin{array}{l}42.978 \\
(21.150)\end{array}$ & $\begin{array}{l}43.675 \\
(20.708)\end{array}$ & $\begin{array}{l}28.597 \\
(17.197)\end{array}$ \\
\hline$A G E S$ & $\begin{array}{l}1924.697 \\
(1695.810)\end{array}$ & $\begin{array}{l}1807.414 \\
(1609.959)\end{array}$ & $\begin{array}{l}2294.001 \\
(1919.869)\end{array}$ & $\begin{array}{l}2334.506 \\
(1943.979)\end{array}$ & $\begin{array}{l}1113.524 \\
(1372.177)\end{array}$ \\
\hline PRIMARY & $\begin{array}{l}0.179 \\
(0.384)\end{array}$ & $\begin{array}{l}0.129 \\
(0.335)\end{array}$ & $\begin{array}{l}0.188 \\
(0.391)\end{array}$ & $\begin{array}{l}0.208 \\
(0.407)\end{array}$ & $\begin{array}{l}0.178 \\
(0.383)\end{array}$ \\
\hline SECONDARY & $\begin{array}{l}0.274 \\
(0.446)\end{array}$ & $\begin{array}{l}0.273 \\
(0.445)\end{array}$ & $\begin{array}{l}0.162 \\
(0.369)\end{array}$ & $\begin{array}{l}0.368 \\
(0.483)\end{array}$ & $\begin{array}{l}0.239 \\
(0.426)\end{array}$ \\
\hline$H I G H$ & $\begin{array}{l}0.130 \\
(0.336)\end{array}$ & $\begin{array}{l}0.273 \\
(0.445)\end{array}$ & $\begin{array}{l}0.021 \\
(0.143)\end{array}$ & $\begin{array}{l}0.048 \\
(0.213)\end{array}$ & $\begin{array}{l}0.064 \\
(0.245)\end{array}$ \\
\hline$U N M A R$ & $\begin{array}{l}0.308 \\
(0.462)\end{array}$ & $\begin{array}{l}0.379 \\
(0.485)\end{array}$ & $\begin{array}{l}0.265 \\
(0.442)\end{array}$ & $\begin{array}{l}0.260 \\
(0.439)\end{array}$ & $\begin{array}{l}0.555 \\
(0.497)\end{array}$ \\
\hline \multicolumn{6}{|c|}{ Males' Employment Status } \\
\hline EMPLOYER & $\begin{array}{l}0.022 \\
(0.148)\end{array}$ & $\begin{array}{l}0.018 \\
(0.134)\end{array}$ & $\begin{array}{l}0.012 \\
(0.109)\end{array}$ & $\begin{array}{l}0.013 \\
(0.113)\end{array}$ & $\begin{array}{l}0.013 \\
(0.115)\end{array}$ \\
\hline EMPLOYEE & $\begin{array}{l}0.425 \\
(0.494)\end{array}$ & $\begin{array}{l}0.407 \\
(0.492)\end{array}$ & $\begin{array}{l}0.214 \\
(0.410)\end{array}$ & $\begin{array}{l}0.251 \\
(0.435)\end{array}$ & $\begin{array}{l}0.243 \\
(0.429)\end{array}$ \\
\hline SELF EMPL & $\begin{array}{l}0.207 \\
(0.405)\end{array}$ & $\begin{array}{l}0.156 \\
(0.363)\end{array}$ & $\begin{array}{l}0.395 \\
(0.489)\end{array}$ & $\begin{array}{l}0.346 \\
(0.477)\end{array}$ & $\begin{array}{l}0.236 \\
(0.425)\end{array}$ \\
\hline UNPAID & $\begin{array}{l}0.039 \\
(0.194)\end{array}$ & $\begin{array}{l}0.026 \\
(0.159)\end{array}$ & $\begin{array}{l}0.111 \\
(0.315)\end{array}$ & $\begin{array}{l}0.043 \\
(0.204)\end{array}$ & $\begin{array}{l}0.132 \\
(0.338)\end{array}$ \\
\hline OTHERS & $\begin{array}{l}0.004 \\
(0.066)\end{array}$ & $\begin{array}{l}0.003 \\
(0.051)\end{array}$ & $\begin{array}{l}0.006 \\
(0.077)\end{array}$ & $\begin{array}{l}0.013 \\
(0.113)\end{array}$ & $\begin{array}{l}0.005 \\
(0.073)\end{array}$ \\
\hline \multicolumn{6}{|c|}{ Household Characteristics } \\
\hline FTYPE & $\begin{array}{l}0.473 \\
(0.499)\end{array}$ & $\begin{array}{l}0.568 \\
(0.496)\end{array}$ & $\begin{array}{l}0.484 \\
(0.500)\end{array}$ & $\begin{array}{l}0.468 \\
(0.500)\end{array}$ & $\begin{array}{l}0.496 \\
(0.500)\end{array}$ \\
\hline HOUSE & $\begin{array}{l}0.406 \\
(0.491)\end{array}$ & $\begin{array}{l}0.352 \\
(0.478)\end{array}$ & $\begin{array}{l}0.537 \\
(0.499)\end{array}$ & $\begin{array}{l}0.593 \\
(0.492)\end{array}$ & $\begin{array}{l}0.334 \\
(0.472)\end{array}$ \\
\hline \multicolumn{6}{|c|}{ Economic Status of the Household } \\
\hline PERINCOM & $\begin{array}{l}11953.979 \\
(15613.67 \\
0)\end{array}$ & $\begin{array}{l}15598.100 \\
(21514.73 \\
\text { 9) }\end{array}$ & $\begin{array}{l}3902.552 \\
(4538.921)\end{array}$ & $\begin{array}{l}4191.775 \\
(3890.922)\end{array}$ & $\begin{array}{l}5931.849 \\
(8660.995)\end{array}$ \\
\hline Sample Size & 1378 & 769 & 1006 & 231 & 11358 \\
\hline & $\begin{array}{l}\begin{array}{l}9.3 \\
\text { cent }\end{array} \\
\end{array}$ & $\begin{array}{l}\begin{array}{l}5.2 \\
\text { cent }\end{array} \\
\end{array}$ & $\begin{array}{ll}\begin{array}{l}6.8 \\
\text { cent }\end{array} & \text { per } \\
\end{array}$ & $\begin{array}{l}1.6 \\
\text { cent }\end{array}$ & 77 per cent \\
\hline
\end{tabular}

Source: Pakistan Integrated Household Survey (1998-99)

Note: Numbers in parentheses are standard deviations. 
Muhammad Akram, Lubna Shahnaz and Surayya 105

Table: 3 Multinomial Logit Estimates for Punjab’s Sample $(N=14742)$

\begin{tabular}{|c|c|c|c|c|c|}
\hline Variables & $\boldsymbol{R} U \boldsymbol{M}$ & $\boldsymbol{U U M}$ & $R R M$ & URM & $N M$ \\
\hline \multirow[t]{3}{*}{ Constant } & -0.262 & -0.184 & -0.160 & -0.067 & 0.672 \\
\hline & -4.243 & -5.108 & -3.514 & -5.517 & \\
\hline & $(-18.503)^{* *}$ & $(-17.019)^{* *}$ & $(-13.257)^{* *}$ & $(-10.240)^{* *}$ & \\
\hline \multicolumn{6}{|c|}{ Males' Characteristics } \\
\hline \multirow[t]{2}{*}{$A G E 1$} & 0.006 & 0.002 & 0.003 & 0.000 & -0.011 \\
\hline & $\begin{array}{l}0.083 \\
(8.247)^{* *}\end{array}$ & $\begin{array}{l}0.069 \\
(5.269)^{* * *}\end{array}$ & $\begin{array}{l}0.604 \\
(5.533)^{* *}\end{array}$ & $\begin{array}{l}0.050 \\
(2.285)^{* * *}\end{array}$ & \\
\hline \multirow[t]{3}{*}{$A G E S$} & -0.000 & -0.000 & -0.000 & -0.000 & 0.000 \\
\hline & -0.005 & -0.003 & -0.003 & -0.001 & \\
\hline & $(-5.168)^{* *}$ & $(-2.518)^{*}$ & $(-2.758)^{* *}$ & $(-0.619)$ & \\
\hline \multirow[t]{3}{*}{ PRIMARY } & 0.005 & 0.005 & -0.014 & 0.008 & -0.004 \\
\hline & 0.072 & 0.124 & -0.202 & 0.504 & \\
\hline & $(0.846)$ & $(0.990)$ & $(-2.244)^{* *}$ & $(2.707)^{* *}$ & \\
\hline \multirow[t]{3}{*}{ SECONDARY } & $Y \quad 0.007$ & 0.024 & -0.039 & 0.014 & -0.005 \\
\hline & 0.104 & 0.514 & -0.591 & 0.902 & \\
\hline & $(1.361)$ & $(4.936)^{* *}$ & $(-6.177)^{* *}$ & $(5.476)^{* *}$ & \\
\hline \multirow[t]{3}{*}{$H I G H$} & -0.000 & 0.060 & -0.081 & 0.005 & 0.016 \\
\hline & 0.025 & 1.245 & -1.264 & 0.262 & \\
\hline & $(0.225)$ & $(10.190)^{* *}$ & $(-5.471)^{* *}$ & $(0.783)$ & \\
\hline \multirow[t]{3}{*}{$U N M A R$} & -0.009 & 0.009 & -0.017 & 0.002 & 0.016 \\
\hline & -0.124 & 0.157 & -0.283 & & \\
\hline & $(-1.135)$ & (1.098) & $(-2.027)^{* *}$ & $\begin{array}{l}0.071 \\
(0.259)\end{array}$ & \\
\hline
\end{tabular}

Males' Employment Status

$\begin{array}{llllll}\text { EMPLOYER } & \mathbf{- 0 . 0 0 2} & \mathbf{- 0 . 0 4 0} & \mathbf{0 . 0 0 9} & \mathbf{- 0 . 0 0 3} & \mathbf{0 . 0 3 6} \\ & -0.121 & -0.897 & 0.088 & -0.224 & \\ \text { EMPLOYEE } & (-0.538) & (-2.773)^{* *} & (0.283) & (-0.373) & \\ & \mathbf{0 . 0 3 4} & \mathbf{0 . 0 0 2} & \mathbf{- 0 . 0 0 4} & \mathbf{- 0 . 0 0 1} & \mathbf{- 0 . 0 3 1} \\ & 0.441 & 0.129 & -0.019 & -0.036 & \\ \text { UNPAID } & (6.480)^{* *} & (1.427) & (-0.208) & (-0.216) & \\ & \mathbf{- 0 . 0 6 2} & \mathbf{- 0 . 0 6 2} & \mathbf{0 . 0 2 1} & \mathbf{- 0 . 0 1 3} & \mathbf{0 . 1 1 6} \\ & -0.951 & -1.533 & 0.143 & -1.056 & \\ \text { OTHERS } & (-6.348)^{* *} & (-6.471)^{* *} & (1.206) & (-3.089)^{* *} & \\ & \mathbf{- 0 . 0 0 9} & \mathbf{- 0 . 0 2 5} & \mathbf{0 . 0 0 1} & \mathbf{0 . 0 1 5} & \mathbf{0 . 0 1 9} \\ & -0.158 & 0.565 & 0.007 & 0.909 & \\ & (-0.361) & (-0.776) & (0.015) & (1.503) & \end{array}$


106 The Labore Journal of Economics, Vol.7, No.2

Household Characteristics

$\begin{array}{llllll}\text { FTYPE } & \mathbf{0 . 0 0 1} & \mathbf{0 . 0 2 2} & \mathbf{0 . 0 0 9} & \mathbf{0 . 0 0 0} & \mathbf{- 0 . 0 3 2} \\ & 0.081 & 0.503 & 0.183 & 0.083 & \\ & (1.294) & (6.116)^{* *} & (2.525)^{* *} & (0.586) & \\ \text { HOUSE } & \mathbf{- 0 . 0 5 4} & \mathbf{- 0 . 0 3 9} & \mathbf{- 0 . 0 0 5} & \mathbf{0 . 0 0 2} & \mathbf{0 . 0 9 6} \\ & -0.809 & -1.015 & -0.232 & -0.055 & \\ & (-10.361)^{* *} & (-9.683)^{* *} & (-2.463)^{* *} & (-0.030) & \end{array}$

Economic Status of the Household

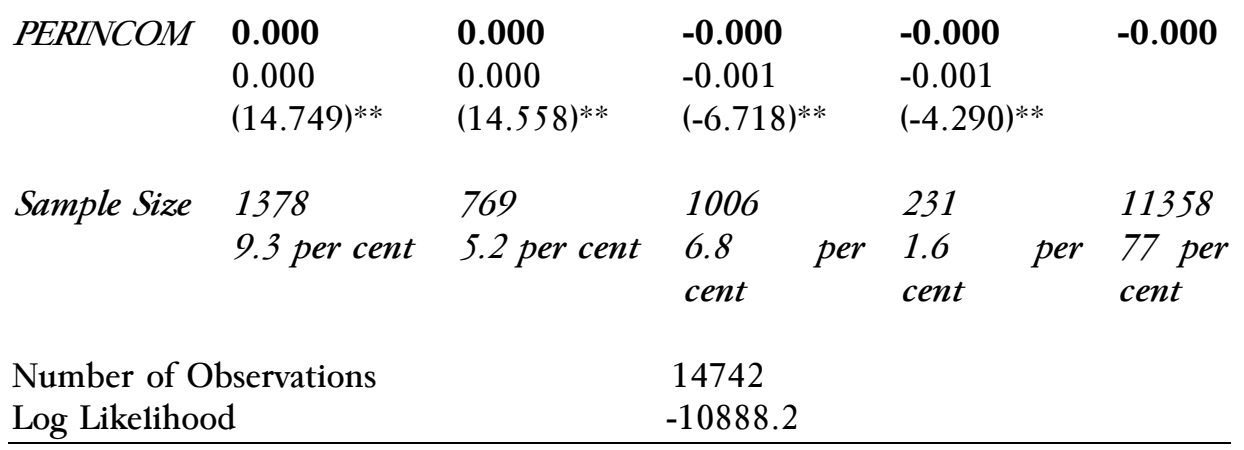

Note: Bold letters represent the partial derivatives at the mean of the dependent variables.

** Indicates significant at the 5 per cent level and * indicates significant at the 10 per cent level. 


\section{References}

Agesa and Richard U, 2000 The Incentive for Rural to Urban Migration a Reexamination of Harris - Todaro Mode1. Applied Economics Letters, 7:2 107-111.

Ahmed, Ather Maqsood and 1smail Siragldin 1994 International Migration, Earnings and the Importance of Self-selection . Pakistan Development Review 33:3 211-227.

Akram Muhammad, Surayya and Lubna Shahnaz, 2001 Factors Affecting Male Internal Migration in Pakistan. Paper presented at the $2^{\text {nd }}$ Annual Conference of Population Association of Pakistan "Pakistan Population Stabilisation Prospects" $31^{\text {st }}$ October to $2^{\text {nd }}$ November 2001, Islamabad, Pakistan.

Greene, William H., 1992 Econometric Analysis. Second Edition. New York: Macmillan Publishing Company.

Irfan. M, 1986 Migration and Development in Pakistan: Some Selected Issues. Pakistan Development Review 25:4 743-755.

Irfan. M. Lione1 Demery and G. M. Arif, 1983 Migration Patterns in Pakistan: Preliminary results from the PLM Survey, 1979. Pakistan Institute of Development Economies: Studies in Population Labor Force and Migration Project. Report No. 6.

Khan, H. Aliya and Lubna Shahnaz, 2000 Determinants of Internal Migration in Pakistan: Evidence from the Labour Force Survey 199697. Pakistan Development Review 39:4 695-712

Perveen, Azra, 1993 Inter-Provincial Migration Pakistan, 1971-1981. Pakistan Development Review 32:4 725-735.

Pakistan, Government of 1998 The 1998 Census Report of Pakistan. Islamabad: Population Census Organisation.

Sjaastad, L. A., 1962 The Costs and Returns of Human Migration. Journal of Political Economy 70:5 80-93.

Todaro. M., 1969 A Model of Labor Migration and Urban Unemployment in Less Developed Countries. The American Economic Review 59:1 138-148.

Marwat, Himayatullah, 1998 Urbanization and its Concomitant Hazards'. Pakistan , $2^{\text {nd }}$ September 1998. 